\section{What ethical difference does an apostrophe make? Balancing the interests of patients and dental professionals}

\author{
P. Affleck, ${ }^{* 1}$ C. Hird, ${ }_{1}^{2}$ C. Potter ${ }^{3}$ and R. Baker ${ }^{4}$
}

IN BRIEF

- Encourages reflection on the ethical obligation of putting patient interests first.

- Provides a more nuanced understanding of this obligation.

- Suggests what other obligations and interests are relevant to dental professionals.

Dental professionals are obliged to put the interests of patients first. This is certainly laudable but it is unclear how far this duty extends. A further concern is whether it relates to the interests of a practitioner's own patients or to patients in general. The particular placement of an apostrophe in the General Dental Council's guidance is ambiguous. Dental professionals also have their own interests and might well ask if those interests should always be superseded. Every dental professional has a responsibility to put patient interests first as part of their professional registration; understanding this duty is therefore vital.

The General Dental Council's (GDC) first principle, stated in its Standards for dental professionals, ${ }^{1}$ is 'putting patients' interests first and acting to protect them'. This seems straightforward, putting patient interests before your own interests and the interests of other people more generally. However, it is ambiguous. Does it refer to the patient in front of you in the dental chair, to every patient within your practice or to dental patients as a category of people?

The Apostrophe Protection Society ${ }^{2}$ gives two uses for their titular punctuation mark. Firstly, the apostrophe indicates a missing letter or letters. Secondly, the apostrophe denotes possession. One of the examples they give for this latter use is 'Jones's bakery'. However, they qualify this with, 'but Joneses' bakery if owned by more than one Jones'. GDC guidance places the apostrophe after the letter ' $\mathrm{s}$ ' in patients suggesting that it could be the interests of patients in general that need to be protected.

\footnotetext{
'Leeds Cancer Research UK Centre, Section of Epidemiology and Biostatistics, Leeds Institute of Molecular Medicine, Cancer Genetics Building, St. James's University Hospital, Leeds, LS9 7TF; ${ }^{2}$ Clinical Teaching Fellow, ${ }^{3}$ Senior Clinical Teaching Fellow, ${ }^{4}$ Dental Education Adviser, Leeds Dental Institute, Clarendon Way, Leeds, LS2 9LU

${ }^{*}$ Correspondence to Paul Affleck

Email: p.a.affleck@leeds.ac.uk; Tel: +44 1132066527
}

\section{Refereed Paper}

Accepted 17 October 2012

DOI: 10.1038/sj.bdj.2013.51

${ }^{\bullet}$ British Dental Journal 2013; 214: 51-53
It could be argued that protecting the interests of patients in general inevitably entails protecting the interests of individual patients. However, the placement of the apostrophe suggests that dental professionals have obligations that extend beyond the clinical relationship they have with their own patients. For example, if they have concerns about the care given by colleagues then they have to place the interests of those patients above the interests of their colleagues. This tallies with other GDC guidance documents such as Principles of raising concerns. ${ }^{3}$ This document makes it clear that all dental professionals have a responsibility to raise concerns about the behaviour of a colleague or an employer that may be placing patients at risk.

This concern for patients collectively raises a number of other issues. It might be thought that when you accept a patient you are accepting a range of ethical obligations to that individual. But if dental professionals have a duty to all patients, how is this generated? Plausibly, it is an obligation that is incurred with professional registration; to practise as a professional you have to agree to abide by a professional code. Professions have privileges beyond those of other occupations (such as self-regulation and a high degree of autonomy) and those privileges come with special duties. Still, it might be considered unreasonable to expect a dental professional to have such a wide-ranging duty. Also, is it fair to expect a dental professional to always put the interests of patients first?

Some dental professionals undertake voluntary work using their professional skills. For example, giving health promotion talks to schoolchildren or working in a free clinic for the homeless at Christmas. Such activities are certainly laudable and put patient interests first, but most patients would probably not see them as something that dental professionals have to do. The line between what is optional (yet praiseworthy) and what is required is unclear. It is tempting to say that anything that does not fall within the scope of an employment or other financial contract is voluntary and optional. However, if this is the case a professional code becomes superfluous - the dental professional simply needs to look at their contractual commitments to determine their behaviour. If we feel that a code maps out wider responsibilities we have to determine where the professional responsibilities of dental professionals end. Of course, this dilemma is not exclusive to dental professionals, other occupations with a public service ethos such as medicine or policing, face the same issue. For example, whether an off duty doctor or police officer is expected to intervene if they witness an accident.

Codes of conduct are a common feature of professions and reflect professional autonomy. They can also support professionals when they have ethical concerns 
in the workplace; a code demonstrates what the profession expects and can be cited when raising concerns. However, this simply brings us back to our original concern - how to interpret the code. The Standards for dental professionals document does state that the "principles should influence all areas and stages of your professional education and practice', ${ }^{1}$ perhaps implying that they do not extend beyond the world of work. The question of integrity and whether it is possible to apply different standards to personal and professional life is intriguing. To return to the issue of raising concerns, if we expect a dental professional to raise concerns that stem from a conversation with a colleague in the workplace, would it really make any difference if the conversation had been in a pub?

The statement 'putting patients' interests first and acting to protect them' ${ }^{1}$ is ambiguous as to whether it is patients, or the interests of those patients, that should be protected. It might be said that they amount to the same thing, with a person being considered the sum of their interests. However, simply protecting patients could be seen as a negative duty of not doing them harm. This would be a far narrower duty than protecting all of their interests. Even if we accept this 'narrow' duty, issues of access to dental treatment would still arise. When asked in a recent survey ${ }^{4}$ over 50\% of British adults were concerned that they would not be able to afford dental care in the future. Does this mean that the cost of treatment actually places patients at risk or are there more complex factors at work?

One complicating factor is how dental services are organised in the UK. Unlike visiting a general practitioner, most people have to pay to visit their dentist with the charge depending on whether they are registered as a private patient or an NHS patient. This financial relationship between the patient and the practitioner creates ethical tensions that do not typically exist between doctors and patients in the UK. The dental professional has a financial relationship with most of their patients as well as a therapeutic one.

Many dental practices are small businesses and so some dental professionals will have to balance employing staff and managing cash flow along with the interests of their patients. It is not obvious that patient interests can or should always be put before the interests of staff or the practice. It might be decided to increase dental charges to bring the practice more in line with the local average for private practices. This may enable a small increase in staff wages or even just a better return for the practice owner.

From a patient perspective the current remuneration of dental professionals might not seem to be in line with their interests, since that remuneration comes out of the charges they pay. Given that the median gross earnings for full-time UK employees in 2011 were $£ 26,500,{ }^{5}$ presumably most patients earn a great deal less than their dentist. It can be plausibly argued that dental earnings are a fair reflection of a long training period, high technical skill and considerable responsibility. Also, the earnings of dental professionals vary greatly. However, the current issue is whether the level of remuneration is compatible with putting patients' interests first. A highly paid practitioner could perhaps argue that high personal remuneration helps to maintain standards, as it encourages ambitious individuals into the profession, safeguarding patient interests. However, such a strategy appears likely to attract individuals who put their own (financial) interests first. Alternatively, they could plausibly argue that the interests of patients and the interests of the profession have to be balanced. However, this could mean that patient interests will not always be put first.

If we accept that there are times when patient interests are not put first we have to establish what principle, or principles, would allow them to be superseded. In Standards for dental professionals ${ }^{1}$ the GDC itself identifies one justification in the form of the public interest. If disclosure can protect other individuals from harm it may be necessary even if it is not in the interests of the patient. This suggests that the interests of all individuals are important and that would include the interests of dental professionals. From this perspective a commitment to putting patient interests first is a pro tanto duty - a definite obligation but one that can be overruled by a more pressing obligation.

Dental professionals should always look to see where the interests of patients lie. Those interests should be protected unless there is a clear justification for overriding them. Where the safety of staff or the public are at stake then the case is clear. When it comes to remuneration of dental professionals and whether dental professionals have responsibilities outside the clinic it becomes more difficult. It could be argued that a shift towards more salaried dental professionals would reduce potential conflicts of interest and enable greater focus on patient interests. However, this has implications for professional autonomy. A further issue is patient autonomy; whether the individual patient or their dental team is the judge of patient interests. There is not enough room here to explore this issue, but there is certainly a tension between patient autonomy and professional autonomy.

In many respects the documents of the GDC are a model for other professions to follow. There is an art to writing guidance for professional conduct - it must be comprehensive while remaining clear and concise. The guidance cannot be too prescriptive because of the wide range of possible scenarios. Also, one of the defining characteristics of a professional is autonomy - the ability to use independent judgement. Therefore the guidance has to set out basic principles that define the profession's ethos and that the individual professional can apply. However, it is unrealistic, and possibly undesirable, for dental professionals to always put patients' interests first.

We are grateful to the students of the Leeds Dental Institute as this article was stimulated by group discussions of what it is to be a professional.

1. General Dental Council. Standards for dental professionals. London: GDC, 2005. Online article available at www.gdc-uk.org/Newsandpublications/Publications/ Publications/StandardsforDentalProfessionals[1].pdf (accessed January 2013).

2. Apostrophe Protection Society. The correct use of the apostrophe in English. Online article available at http://www.apostrophe.org.uk/page2.html (accessed January 2013).

3. General Dental Council. Principles of raising concerns. London: GDC, 2006. Online article available at http://www.gdc-uk.org/Newsandpublications/ Publications/Publications/RaisingConcerns[1].pdf (accessed January 2013).

4. Simplyhealth. Simplyhealth's annual dental survey 2012. Andover: Simplyhealth, 2012. Online survey available at https://www.simplyhealth.co.uk/shcore/ sh/content/pdfs/surveys/report_dentalsurvey_2012. pdf (accessed January 2013).

5. Office of National Statistics. 2012 annual survey of hours and earnings. London: ONS, 2012. Online survey available at http://www.ons.gov.uk/ons/ dcp171778_286243.pdf (accessed January 2013). 